\title{
Top-down inhibition of search distractors in parallel visual search
}

\author{
Hermann J. Müller \\ Ludwig Maximilians University, Munich, Germany, \\ and Birkbeck College, University of London, London, England \\ AdRIAN VON MÜHLENEN \\ Ludwig Maximilians University, Munich, Germany, \\ and University of Warwick, Warwick, England \\ AND \\ ThOMAS GeYer \\ Ludwig Maximilians University, Munich, Germany
}

\begin{abstract}
In three experiments, we examined distractor inhibition in parallel ("pop-out") visual search. Distractor inhibition was measured in terms of reaction time (RT) to a simple luminance increment probe presented, after the search task response, at display locations that either contained a search distractor (on-probe) or were blank (off-probe). When the search stimuli remained in view, the on-probe (relative to off-probe) RT cost was larger than in a baseline condition in which observers had only to passively view, rather than search, the display. This differential on-probe RT cost, which discounts effects of masking, was interpreted as a measure of distractor inhibition associated with target selection in parallel visual search. Taken together, the results argue that the distractor inhibition is an object-based and local phenomenon that affects all distractors (of a particular type) in an equal manner.
\end{abstract}

Although it is now generally accepted that "inhibition of return" (IOR) to distractor locations influences serial visual search (see, e.g., Danziger, Kingstone, \& Snyder, 1998; Klein, 1988; Müller \& von Mühlenen, 2000), recent findings argue that some types of distractor inhibition (other than IOR) also operate in parallel, "pop-out" search. Evidence for this comes from studies that have investigated inhibitory priming across search trials (for reviews, see Chun \& Nakayama, 2000; Shore \& Klein, 2000). The key finding was that when the current (Trial $n$ ) target-defining attribute was the same as a previous (Trial $n-i)$ distractor attribute, target detection was impeded relative to when the current target was defined by a repeated target attribute. Such inhibitory cross-trial priming effects were reported for stimulus features such as color and spatial frequency (Maljkovic \& Nakayama, 1994, 2000), stimulus dimensions (e.g., Found \& Müller, 1996; Wolfe, Butcher, Lee, \& Hyle, 2003), and, importantly in the present context, stimulus positions (e.g., Kumada \& Humphreys, 2002; Maljkovic \& Nakayama, 1996). ${ }^{1}$

Positional distractor inhibition in parallel search has also been demonstrated by Cave and his colleagues, who used a probe detection paradigm, rather than examining cross-trial effects (Cepeda, Cave, Bichot, \& Kim, 1998; Kim \& Cave, 1995, 1999). Specifically, in Cepeda et al.'s
Experiment 4, the observers' primary task was to respond to the orientation of a singleton color target. For half of the observers, the singleton target was red (with green distractors), and vice versa for the other half. The search displays consisted of four briefly presented (98-msec) stimuli: one target and three distractors forming a geometrically regular, "square" arrangement (i.e., they were placed on a virtual circle around fixation, with equal interitem spacing); a probe dot was presented on $50 \%$ of the trials $(140,182$, or $224 \mathrm{msec}$ after search display offset). On such trials, the probe appeared at the location of the target or a distractor or an empty stimulus location. The observers' secondary task was to make a simple speeded response to the presence of the probe (go/no-go task). Probe reaction times (RTs) in the search condition were compared with performance in a baseline condition in which all four stimuli were presented in the same color and observers had only to detect the probe. This baseline was meant to account for effects of masking caused by the presentation of the probe at a former stimulus location, as opposed to a blank location. For the search condition, Cepeda et al. found that probe RTs were fastest when the probe appeared at the target location and slowest when it was presented at a distractor location, relative to a blank location. For the baseline condition, no significant RT difference was found

T. Geyer, geyer@Imu.de 
between probes presented at stimulus locations versus blank locations. Cepeda et al. took these findings to argue that distractor inhibition operates in parallel visual search (RT difference between probes presented at distractor vs. blank locations in the search condition) and that it cannot be attributed to visual masking (no RT difference between probes presented at stimulus vs. empty locations in the baseline condition).

Note that Cepeda et al. (1998) used a response procedure different from the one used in Klein's (1988) "classical" paradigm developed to examine distractor inhibition in visual search, in which presentation of a probe stimulus was triggered by a speeded search task ("target-present"/ "target-absent") response. In Cepeda et al., after presentation of the search stimuli (for $98 \mathrm{msec}$ ), the observers had to first perform the probe detection task (speeded response) and only then report the orientation of the singleton target (nonspeeded response). That is, the observers had to actively maintain target features - at least the response-critical orientation-in (visual) short-term memory in order to make a correct response in the primary task. Given that stimuli are encoded conjunctively into visual short-term memory (VSTM; see, e.g., Luck \& Vogel, 1997), other features of the singleton target - in particular, its color (target-defining feature) and location (automatically coded by the singleton's capturing focal attention) would have been maintained as well. By keeping these features in mind, the observers may have also maintained distractor features, at least their color and locations, which were "logically" related to the target features: The distractor color was the "opposite" of the target color, and the distractors were located at those corners of the square not occupied by the target. These task demands (maintaining target and distractor features in VSTM) may have played an important role in the emergence of the positional facilitation (target location) and inhibition (distractor locations) effects in the probe detection task (see, e.g., Olivers, Meijer, \& Theeuwes, 2006, and Soto \& Humphreys, 2007, for the influence of short-term memory contents on visual search performance).

Importantly, in this context, Geyer, Müller, and Krummenacher (2007) have recently shown that regularity of distractor - relative to target - arrangement is a prerequisite for inhibitory cross-trial priming of distractor locations to be observed in pop-out search (cf. Maljkovic \& Nakayama, 1996): There is no inhibitory priming when the distractor arrangement is irregular and varying randomly across trials. (Furthermore, even with regular stimulus layout, there is no inhibitory priming when the number of display items exceeds four.) Geyer et al. concluded from this finding that the inhibition of distractor locations is based on observers' placing inhibitory tags on nontarget locations by applying (top down) a regular spatial frame (equilateral triangle, square) to the display anchored on the target location. Similar mechanisms may very well have been at work in the study of Cepeda et al. (1998), who used a square display arrangement.

Thus, there are at least four questions not conclusively answered by Cepeda et al. (1998). (1) Does distractor inhibition in parallel visual search (as demonstrated by
Cepeda et al., 1998) extend to spatially irregular display arrangements with more than four items? (2) Is it observed on target-absent (as well as on target-present) trials, on which it cannot be anchored on a target location? (3) Is it location or object based? Concerning the latter question, although Cepeda et al. observed slowed responses to probes presented at distractor locations after removal of the distractors (which were displayed for only $98 \mathrm{msec}$ ), it remains a possibility that this was so only because observers maintained a memory (based on a regular spatial frame) of the distractor locations. And (4), related to question (3), is it a within-trial effect that does not carry over into the next trial or a cross-trial effect? (For a distinction between within- and cross-trial memory in visual search, see, e.g., Shore \& Klein, 2000.)

\section{Overview of the Experiments}

Given these open issues, we designed the present study to reinvestigate the mechanism(s) of positional distractor inhibition in parallel visual search. Importantly, in contrast to previous studies (e.g., Cepeda et al., 1998), we examined positional inhibition by presenting random, irregular stimulus arrangements and focusing on target-absent search trials. The latter was intended to yield a clearer measure of distractor inhibition, not influenced by processes of target selection (Geyer et al., 2007). Furthermore, all of the experiments employed a modification of Klein's (1988) paradigm, following the parallel search condition used by Müller and von Mühlenen (2000). That is, the observers performed the search task (making a "targetpresent"/“target-absent" response) prior to the probe detection task, with randomly chosen search stimulus locations (and a randomly selected number of stimuli) on each trial. This was done to do away with any need to actively maintain in memory the layout of the search display and to make it impossible to geometrically derive the distractor locations from knowing the target location. Experiment 1 tested whether distractor inhibition could be observed in a parallel search condition (1) when the search display was extinguished after the observers' search task response, (2) when parts of the search stimuli were extinguished (causing multiple luminance decrements), while keeping the total number of stimuli constant, and (3) when the search display remained in view at the time the luminance increment probe was presented. To rule out possible forwardmasking effects of the probe stimulus by the preceding search stimuli, we added a control condition in which observers only had to passively view, rather than actively search, the display. The results showed clear evidence of "inhibition" of search distractor stimuli over and above any forward-masking effects when the search display remained in view, and reduced but significant inhibition when only the internal parts of the stimuli were removed after the search task response. In contrast, there was no evidence for distractor inhibition when the search stimuli were extinguished before the probe stimulus was presented.

We designed Experiment 2 to rule out the possibility that the distractor inhibition effects observed in Experiment 1 were caused by eye movements during the search. Experiment 1 had revealed no on-probe costs for targets 
(only costs for distractors), which could be due to the fact that observers made an eye movement away from central fixation (the position optimal for visual information intake from across the display) to the target. This could, in turn, have diminished the detectability of on-probe stimuli more than that of off-probe stimuli (i.e., regardless of whether the on-probe stimuli appeared on a target or a distractor; cf. Zimba \& Hughes, 1987). However, Experiment 2 produced evidence for a reduced but significant distractor inhibition (and target facilitation), even when observers had to fixate the display center and eye movements were controlled for.

We designed Experiment 3 to test whether the smaller on-probe RT costs in the part-off condition of Experiment 1 were a local effect (confined to the changed stimuli) or a global effect (affecting changed and unchanged stimuli equally). Moreover, Experiment 3 investigated whether the smaller on-probe RT costs on part-offset distractors reflected reduced inhibition or, alternatively, a priority of processing new (i.e., "changed") relative to old (i.e., "unchanged") distractors (cf. Yantis \& Jonides, 1984). Given that the number of items that can be assigned attentional priority is limited to four (e.g., Yantis \& Johnson, 1990), the RT disadvantage for probes presented on changed (i.e., potentially prioritized) search stimuli should be smaller when fewer than four (e.g., two) of the search stimuli items are changed, in comparison with when more (e.g., eight) are changed. Therefore, in Experiment 3, we systematically manipulated the proportion of changed to unchanged distractors. The results revealed reduced costs for changed relative to unchanged distractors, indicating that luminance decrements reduced the inhibition locally. However, the inhibitory effect was found to be independent of the number of changed objects. This finding was taken as evidence that the smaller RT disadvantage for changed relative to unchanged distractors resulted from a reduction in the inhibition associated with them, rather than from their prioritized attentional processing.

Overall, the results of Experiments 1-3 suggest that a process of distractor inhibition, which cannot be explained by forward masking or eye movements alone, plays a crucial role in parallel visual search. The inhibition operates in object-based, rather than spatial, coordinates; it is associated with observers' search task response; and it is a local phenomenon, affecting all distractors of a particular type in an equal and spatially parallel manner.

\section{EXPERIMENT 1}

We designed Experiment 1 to investigate whether distractor inhibition could be observed in parallel visual search when (1) the search stimuli were extinguished after observers' search task response ("display off"), (2) only the internal (nonboundary contour) parts of the search stimuli were removed ("part off"), or (3) the stimuli remained in view until the response to a luminance increment, presented to probe distractor inhibition in the search array ("display on"). These conditions are illustrated in Figure 1. The search displays consisted of varying numbers of outline squares, each containing a corner junction segmenting out their upper right quadrant. The target was defined by a globally different orientation, a $45^{\circ}$ rotation, relative to the distractors. In one condition, parallel search, observers had to discern the presence of this target in the search array ("target-present"/"target-absent" response). Their search task response then triggered the probe detection task, which required a "go" response to the onset of a probe stimulus at a (previously) occupied array location (on-probe) or at an empty location (off-probe), and the withholding of a response when no probe stimulus was presented.

We compared this parallel search condition with a passive-viewing condition, which served as a baseline. The observers were presented with the "search" array for an amount of time comparable to that in the parallel search condition, but they were instructed to simply "look at the display" without performing any search (or other task related to these stimuli). To reinforce this instruction, we made all of the search array stimuli the same-that is, there was never an odd-one-out "target" to capture observers' attention. The stimulus array was presented for a variable period of time between 400 and $800 \mathrm{msec}$ (i.e., within the range taken by observers in the parallel search condition to respond "target absent"), until a detection probe could be presented, either at a (previously) occupied location (on-probe) or an empty location (off-probe). The observers' only task was to respond as quickly as possible to the onset of the probe stimulus.

The rationale for comparing the parallel search condition against the passive-viewing condition followed the technique developed by Klein (1988): Slower RTs to onprobes than to off-probes (henceforth referred to as onprobe RT cost) were expected under both parallel search and passive-viewing conditions, because of visual factors such as masking of on-probe stimuli by the search array stimuli or their sudden offsets (display-off condition). By contrast, such factors should have less (if any) effect on off-probe detection performance. Masking or display-off effects would be equivalent in both parallel search and passive-viewing conditions. However, if distractor inhibition was operating in parallel visual search, the on-probe RT cost in the search condition would also be influenced by inhibition placed on search distractors or their locations. Any such additional component can be estimated by subtracting the on-probe RT in the control condition (in which there can be no distractor inhibition because observers only passively viewed, rather than searched, the display) from the cost in the parallel search condition. If the residual cost (henceforth referred to as differential onprobe $R T$ cost) in the parallel search condition is positive, it can be interpreted as evidence for distractor inhibition. Furthermore, less distractor inhibition was expected when the search items were changed or completely extinguished (see Müller \& von Mühlenen, 2000, for differential IOR effects when the search displays remained in view, were changed, or were extinguished).

\section{Method}

Participants. A total of 20 observers (age range, 21-40 years; 12 of them female), all with normal or corrected-to-normal vision, took part in Experiment 1. Ten observers took part in the search task 


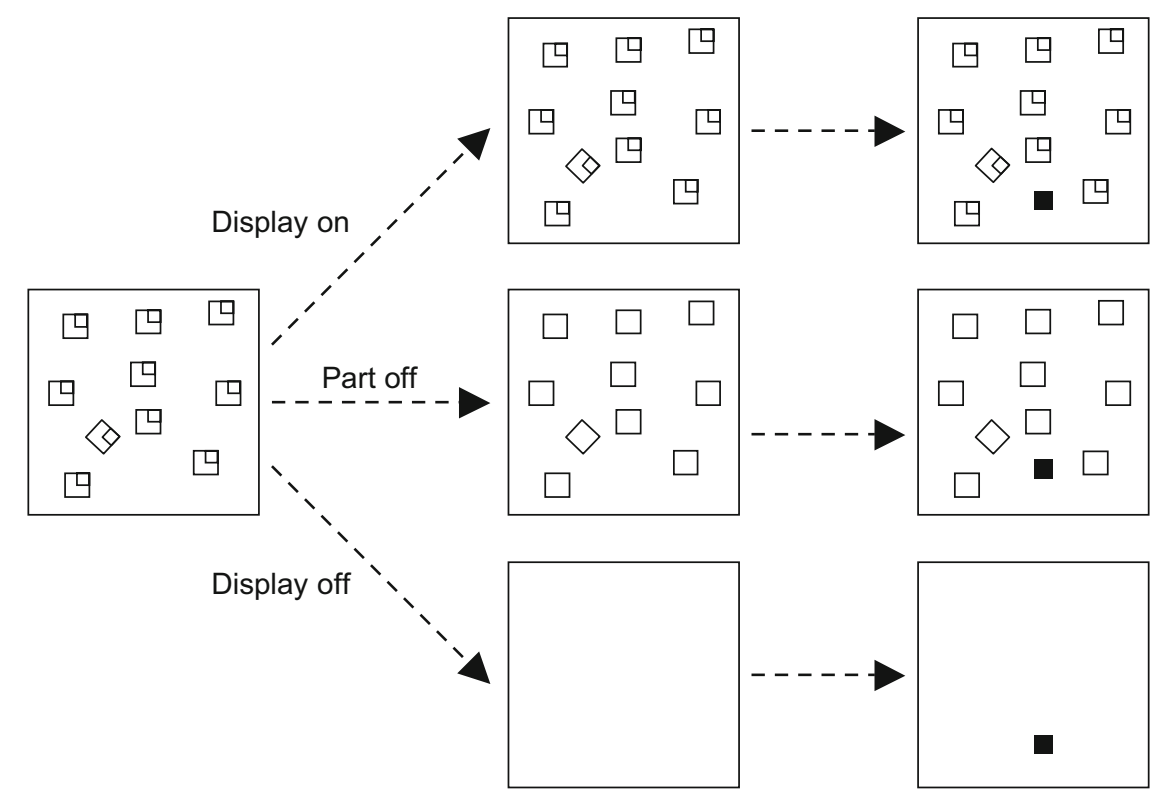

Figure 1. Sequence of frames on a given trial in the display-off (top), display-on (middle), and part-off conditions (bottom) of Experiment 1. The search display depicts a parallel search array consisting of a target and nine distractor stimuli (10-item display; target-present trial). The probe detection display depicts a trial with a luminance increment probe at a previously empty location (off-probe).

condition and were paid $€ 13$ for two 1-h sessions. The other $10 \mathrm{ob}-$ servers took part in the passive-viewing condition and were paid $€ 6.50$ for a 1 -h session.

Apparatus. We conducted the experiment in a dimly lit room, to minimize reflections on the CRT. The stimuli were presented on a Tektronix 608 CRT with a fast-decay P15 phosphor. The oscilloscope was driven by an Interactive Electronics Systems point plotter (Finley, 1985), controlled by a PC. The observers viewed the monitor from a distance of $57 \mathrm{~cm}$, with head position maintained by the use of a chinrest. The observers' search task responses ("target present" or "target absent") were recorded using the right and left buttons of a serial Microsoft mouse, with the track ball removed, to improve timing accuracy (Segalowitz \& Graves, 1990). Their subsequent probe detection responses were recorded by means of a response key interfaced with the PC via the parallel port.

Stimuli. The stimuli were square boxes, with a side length of $0.46^{\circ}$ (luminance, $0.8 \mathrm{~cd} / \mathrm{m}^{2}$; monitor background luminance, $0.1 \mathrm{~cd} / \mathrm{m}^{2}$ ). Each box contained a small corner junction segmenting out its upper right quadrant. There were 2,6 , or 10 stimuli in the display. In the parallel search condition, the target was defined by being the only item standing on one corner (i.e., being rotated by $45^{\circ}$ ), whereas all of the distractors stood on one side. In the passive-viewing condition, in order to reinforce the instruction of passive viewing, we included no target item in the display. The search array stimuli occupied randomly chosen locations defined by the intersections of an invisible grid of $6 \times 6$ lines. The grid covered the central $7.82^{\circ} \times 7.82^{\circ}$ area of the display (with the total display area being $12.4^{\circ} \times 12.4^{\circ}$ ). The luminance increment probe stimulus consisted of a bright, filled square of side length $0.31^{\circ}$, with a luminance of $1.2 \mathrm{~cd} / \mathrm{m}^{2}$. This stimulus was presented either at a location (previously) occupied by a search stimulus (on-probe) or on one of the (previously) empty $6 \times$ 6 grid locations (off-probe). The likelihood of an on-probe stimulus's occurring at the location of the search target was $1 / 10,1 / 6$, and $1 / 2$ for 10-, 6-, and 2-item displays, respectively, to prevent a bias away from the target location. Following the search task response, the search array stimuli could (1) be extinguished (display off), (2) be partly extinguished (part off), or (3) remain entirely in view until the end of the trial (display on). The rationale for this variation was that
Müller and von Mühlenen (2000) had observed distractor inhibition in serial visual search only when the display items remained in view at the time the probe was presented (relative to the display items being partly changed or extinguished). Thus, by using the same display conditions as in Müller and von Mühlenen, Experiment 1 was meant to examine whether and how display changes would influence distractor inhibition in parallel visual search.

Design and Procedure. The observers in the parallel search condition performed a total of 1,440 trials, and the observers in the passive-viewing condition performed 720 trials. The parallel search condition consisted of 80 trials for each display size $(2,6,10) \times$ target (present, absent) $\times$ display change (display on, part off, display off) combination. On half of the trials in each display size $\times$ target $\times$ display change condition (720 trials total), the search task response triggered the presentation of a luminance increment probe. Half of such stimuli were on-probes (360 trials), and half were offprobes (360 trials). There were 20 on-probe and 20 off-probe trials for each display size $\times$ target $\times$ display change combination of the search task. On trials on which no luminance increment stimulus appeared ( 720 "catch" trials), the search task response initiated the next trial. Within the search condition, all of the trial types were presented in randomized order.

The passive-viewing condition consisted of 720 trials, with 80 trials for each display size $(2,6,10) \times$ display change (display on, part off, display off) condition. In one half of the trials in each condition (360 trials), a probe stimulus was presented; the other half were catch trials (360 trials). The observers were instructed to "look at the display and respond to a probe stimulus as quickly as possible." Note that, on $20 \%$ of probe trials, the probe stimulus was presented "early" - that is, within 100-300 msec (variable) after the onset of the stimulus array, while the stimuli were in view in all conditions. We included such early probe trials to make observers "look at the display" from the start, ${ }^{2}$ but we did not analyze the responses on such trials. All of the trial types were presented in randomized order.

At the start of each trial, a fixation cross was presented for $500 \mathrm{msec}$ in the center of the monitor. After a "blank" interval of $500 \mathrm{msec}$, the search array was displayed until the observers responded "target present" or "target absent" by pressing the right and 
left buttons, respectively, of the mouse, using the middle ("present") and index ("absent") fingers of the right hand. For the display-off condition, the search task response terminated the search array (bottom of Figure 1). In the part-off condition (middle of Figure 1), the internal parts of the search stimuli were removed upon the search task response. In all three display conditions, $60 \mathrm{msec}$ after the search task response, a luminance increment stimulus could be presented. This stimulus was displayed until the observers pressed a single response key with their left-hand index finger. At this point, the detection probe and, in the display-on and part-off conditions, the search array were completely extinguished. On trials on which no detection probe was presented, the search and part-off display or the "blank" display remained in view for 1,000 msec. When observers made an incorrect search task response (target miss or false alarm), they were alerted to the error by a brief computer-generated "bleep." No feedback was provided with respect to probe detection errors: probe detection responses on catch trials, or anticipation responses on trials on which a probe was presented (RT less than $100 \mathrm{msec}$ ). The intertrial interval was $1,000 \mathrm{msec}$ if no error signal sounded and $2,000 \mathrm{msec}$ after an error signal.

The physical conditions in the passive-viewing condition closely matched those in the parallel search condition. After a fixation cross was presented for $500 \mathrm{msec}$ and a "blank" interval was presented for $500 \mathrm{msec}$, the search stimuli were presented for a variable time between 400 and $800 \mathrm{msec}$, approximately matching the range of search RT in the parallel search condition. Next, the array of stimuli was extinguished (display-off condition); or the internal corner junctions, but not the external contour, of the stimuli were removed (partoff condition); or the stimuli remained in view (display-on condition). At a time lag of $60 \mathrm{msec}$ after this event (or nonevent, in the display-on condition), a detection probe could be presented, either at a (previously) occupied location (on-probe) or at an empty location (off-probe). On trials on which no detection probe was presented (catch trials), nothing further happened until $1,000 \mathrm{msec}$ after the presentation of the stimulus array (i.e., the display remained completely blank in the display-off condition). In summary, the crucial difference between the parallel search and passive-viewing conditions was one in the observers' task set: No search was to be performed prior to the probe detection task.

The parallel search condition consisted of 18 blocks, divided into two sessions of 9 blocks each, with sessions separated by a break of at least $1 \mathrm{~h}$. The passive-viewing condition consisted of 9 blocks, performed in a single session. Each block had 5 warm-up trials and 80 experimental trials, with blocks separated by short breaks $(10 \mathrm{sec})$.

Probe RT analysis. We analyzed probe detection RTs for evidence of distractor inhibition only on target-absent search trials, according to the technique developed by Klein (1988; see above). Note that we did not analyze probe RTs if they were preceded by an incorrect search task response.

\section{Results}

Search performance. We varied the size of the search display to ascertain that search performance was indeed parallel, rather than serial (the target-present search rate of $4 \mathrm{msec} /$ item, consistent with parallel search). The parallel search condition was affected only by the experimental manipulations of target (absent, present) and display size $(2,6,10$ items); the other manipulation (display change, probe) occurred after the search task response. A two-way ANOVA revealed significant effects of target $[F(1,9)=$

Table 1

Group Mean Correct Reaction Times (RTs, in Milliseconds) in the Parallel Search Condition to On-Distractor and Off-Probes (Columns 2-4; Target-Absent Trials Only), to On-Distractor, On-Target, and Off-Probes (Columns 5-7; Target-Present Trials Only), and to On-Distractor and Off-Probes in the Passive-Viewing Condition (Columns 8-10), Separately for the Display Change Conditions (Display Off, Part Off, Display On) and Display Size Conditions $(2,6,10)$ in Experiment 1, With Corresponding RT Differences (All Display Sizes) Between On- and Off-Probes (On-Probe RT Cost: On-Off) for the Parallel Search and Passive-Viewing Tasks

\begin{tabular}{|c|c|c|c|c|c|c|c|c|c|}
\hline \multirow[b]{3}{*}{ Display Change } & \multicolumn{9}{|c|}{ Search Condition } \\
\hline & \multicolumn{3}{|c|}{$\begin{array}{c}\text { Parallel } \\
\text { Search-Absent }\end{array}$} & \multicolumn{3}{|c|}{$\begin{array}{c}\text { Parallel } \\
\text { Search-Present }\end{array}$} & \multicolumn{3}{|c|}{ Passive Viewing } \\
\hline & On & Part Off & Off & On & Part Off & Off & On & Part Off & Off \\
\hline \multicolumn{10}{|l|}{ Display Size 2} \\
\hline Off-probe & 449 & 428 & 469 & 444 & 402 & 449 & 342 & 343 & 339 \\
\hline On-distractor & 498 & 454 & 500 & 504 & 473 & 498 & 359 & 369 & 369 \\
\hline On-target & & & & 437 & 420 & 470 & & & \\
\hline \multicolumn{10}{|l|}{ Display Size 6} \\
\hline Off-probe & 453 & 409 & 483 & 422 & 405 & 448 & 326 & 353 & 349 \\
\hline On-distractor & 524 & 479 & 542 & 538 & 435 & 490 & 365 & 396 & 399 \\
\hline On-target & & & & 432 & 434 & 490 & & & \\
\hline \multicolumn{10}{|l|}{ Display Size 10} \\
\hline Off-probe & 454 & 399 & 480 & 423 & 402 & 467 & 338 & 350 & 353 \\
\hline On-distractor & 546 & 503 & 505 & 549 & 482 & 526 & 363 & 392 & 403 \\
\hline On-target & & & & 405 & 428 & 465 & & & \\
\hline \multicolumn{10}{|l|}{ Mean } \\
\hline Off-probe & 452 & 412 & 477 & 430 & 403 & 455 & 335 & 349 & 347 \\
\hline On-distractor & 523 & 479 & 516 & 530 & 463 & 505 & 362 & 386 & 390 \\
\hline On-target & & & & 425 & 427 & 475 & & & \\
\hline On-distractor cost & 71 & 67 & 39 & 101 & 60 & 50 & 27 & 37 & 43 \\
\hline On-target cost & & & & -5 & 24 & 20 & & & \\
\hline Inhibition & 44 & 30 & -4 & 74 & 23 & 7 & & & \\
\hline Facilitation & & & & -32 & -13 & -23 & & & \\
\hline
\end{tabular}

Note-Distractor inhibition and target facilitation are estimated by the differential on-probe RT costs between corresponding parallel search and passive-viewing conditions. 
52.07, $\left.M S_{\mathrm{e}}=3,031, p<.01\right]$ and display size $[F(2,18)=$ 25.58, $\left.M S_{\mathrm{e}}=2,013, p<.01\right]$ and a significant target $\times$ display size interaction $\left[F(2,18)=8.03, M S_{\mathrm{e}}=1,474\right.$, $p<.01]$. RTs were faster when the target was present than when it was absent (626 vs. $686 \mathrm{msec}$, respectively), and RTs increased with display size, though less on targetpresent than on target-absent trials (4 vs. $11 \mathrm{msec} / \mathrm{item}$ ). The error rate of $2 \%$ was very low overall, with fewer false alarms than target misses ( $1.0 \%$ vs. $3.0 \%)$.

Probe detection performance. Table 1 presents the mean probe RTs in the search condition (columns 1-6) and passive-viewing condition (columns 7-9). We examined the probe RTs on target-absent trials using a mixed-design ANOVA with the between-subjects factor of task (parallel search, passive viewing) and the within-subjects factors of display change (on, part off, off), display size $(2,6,10)$, and probe (on, off). This ANOVA revealed three effects involving display size to be significant: the display size main effect $\left[F(2,36)=6.35, M S_{\mathrm{e}}=1,127, p<.01\right]$, the display size $\times$ probe interaction $\left[F(236)=13.99, M S_{\mathrm{e}}=\right.$ $480, p<.01]$, and the display size $\times$ task $\times$ probe $\times$ display change interaction $\left[F(4,72)=2.74, M S_{\mathrm{e}}=580, p<\right.$ $.05]$. The main effect of display size was due to slower on-probe RTs with 6- and 10-item displays in comparison with 2-item displays (423 and 424 vs. $410 \mathrm{msec}$ ), with the effect being due mainly to the on-probe RTs ( 451 and 452 vs. $425 \mathrm{msec}$ ), rather than to the off-probe RTs (395 and 395 vs. $396 \mathrm{msec}$ ). Furthermore, as indicated by the fourway interaction, on-probe RTs in the display-on and partoff conditions increased as display size increased, but this increase was more pronounced in the parallel search task (for the display-on condition, 49, 69, and $92 \mathrm{msec}$, and for the part-off condition, 28, 70, and $104 \mathrm{msec}$, for 2-, $6-$, and 10-item displays, respectively) than in the passiveviewing task (display-on condition, 17, 39, and $25 \mathrm{msec}$; part-off condition, 26, 43, and $26 \mathrm{msec}$ ). ${ }^{3}$ Given that there was a probe effect for all display sizes, we combined the probe RT data across display size in subsequent analyses.

With regard to the other factors, the ANOVA above revealed all main effects to be significant: Probes were detected 115 -msec faster in the passive-viewing than in the parallel search condition $\left[F(1,18)=20.01, M S_{\mathrm{e}}=\right.$ $59,318, p<.01]$; on-probe RTs were 48-msec slower than off-probe RTs $\left[F(1,18)=94.99, M S_{\mathrm{e}}=2,133, p<.01\right]$; probe RTs varied with display change, with faster RTs in the part-off condition than in the display-on and displayoff conditions (406 vs. 418 and $433 \mathrm{msec}$, respectively) $\left[F(2,36)=3.74, M S_{\mathrm{e}}=5,572, p<.05\right]$. Furthermore, the task $\times$ display change interaction $\left[F(2,36)=5.59, M S_{\mathrm{e}}=\right.$ $5,572, p<.01]$ was significant, indicating faster probe RTs in the part-off than in the display-on and display-off conditions. However, this effect was observed only in the parallel search condition (445, 487, and $496 \mathrm{msec}$, for part-off, display-on, and display-off conditions), and not in the passive-viewing task $(367,349$, and $369 \mathrm{msec}$, respectively). ${ }^{4}$ Most importantly, the task $\times$ probe interaction $\left[F(1,18)=5.65, M S_{\mathrm{e}}=2,133, p<.05\right]$ and the task $\times$ probe $\times$ display change interaction $[F(2,36)=$ $\left.5.71, M S_{\mathrm{e}}=830, p<.01\right]$ were significant. As can be seen from Figure 2, on-probe RT costs were higher in the

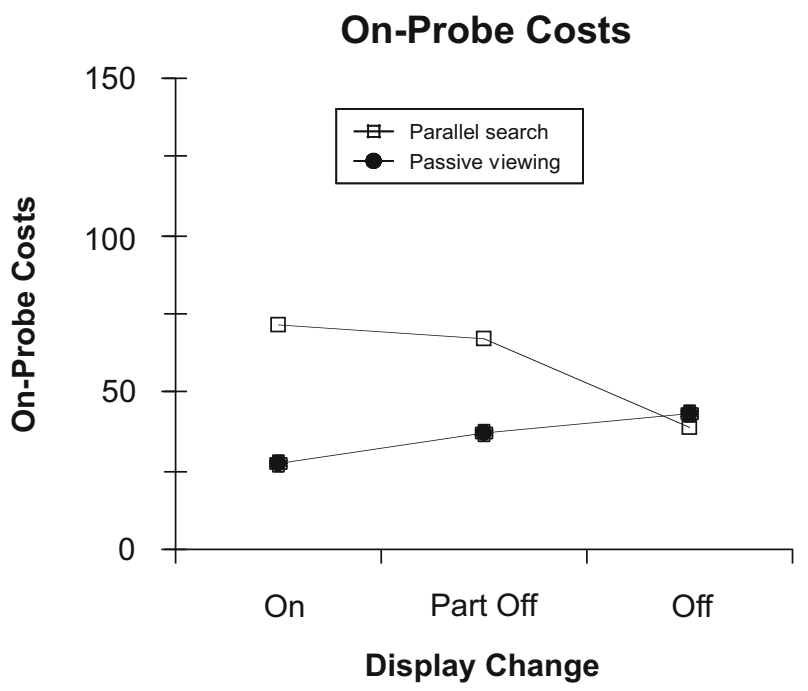

Figure 2. Experiment 1: Reaction time (RT) differences (in milliseconds) between the on- and off-probes (on-probe RT cost) in the parallel search condition (squares) and the passive-viewing condition (circles), separately for the display-on, part-off, and display-off conditions.

parallel search than in the passive-viewing task (59 vs. $36 \mathrm{msec}$, respectively); however, this effect was observed only in the display-on (71 vs. $27 \mathrm{msec})$ and part-off (67 vs. $37 \mathrm{msec}$ ) conditions, but not in the display-off (39 vs. $43 \mathrm{msec}$ ) condition. In other words, distractor inhibition (see Figure 3) was strongest when no changes occurred in the search display (display on: $44 \mathrm{msec}$ ) and intermediate when parts of the stimuli were changed (part off: $30 \mathrm{msec}$ ). No distractor inhibition was evident when the search display was extinguished prior to the presentation of the probe (display off: $-5 \mathrm{msec}$ ). This means that the on-probe RT cost in the display-off condition of the parallel search condition is entirely attributable to local

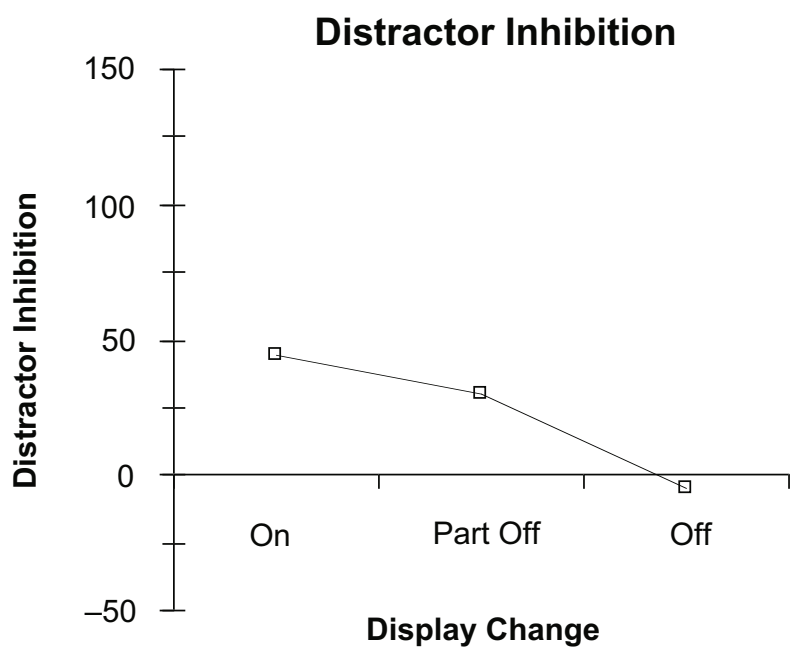

Figure 3. Experiment 1: Differential on-probe reaction time (RT) costs (in milliseconds) between the parallel search condition and the passive-viewing condition (distractor inhibition) in the display-on, part-off, and display-off conditions. 
interference, such as masking. In contrast, in the part-off and display-on conditions of the search task, some other inhibitory component associated with the performance of the task increased the on-probe cost, over and above that expected from local interference.

Probe detection performance in the passiveviewing condition. To further explore the effects in the passive-viewing condition, we carried out a separate ANOVA with the factors probe (on-probe, off-probe) and display change (display off, part off, display on). The ANOVA revealed both main effects to be significant. The probe effect occurred because on-probe RTs were significantly slower than off-probe RTs [379 vs. $344 \mathrm{msec}$; $\left.F(1,9)=42.53, M S_{\mathrm{e}}=454, p<.01\right]$. This means that the greater on-probe RTs in the passive-viewing condition were caused by factors relatively closely confined to the location of the on-probe stimulus (e.g., visual masking). The effect of display change occurred because probes were detected faster in the display-on than in the part-off and display-off conditions [349 vs. 368 and $369 \mathrm{msec}$, respectively; $\left.F(2,18)=5.52, M S_{\mathrm{e}}=452, p<.05\right]$. This indicates that probe detection was disturbed by the changes in the display in the part-off and display-off conditions. This display change effect was even more pronounced for on-probes than for off-probes [362, 386, and $390 \mathrm{msec}$ vs. 335,349 , and $347 \mathrm{msec}$, respectively; $F(2,18)=4.57$, $\left.M S_{\mathrm{e}}=74, p<.05\right]$. This interaction can perhaps be best explained by the effects of two separate factors: the factor "interference," affecting both the on-probe and off-probe conditions, and the factor "masking," affecting only the on-probe condition. Separate one-way ANOVAs revealed the effect of the factor display change to be significant for on-probes $\left[F(2,18)=7.09, M S_{\mathrm{e}}=323, p<.01\right]$, but not for off-probes $\left[F(2,18)=2.68, M S_{\mathrm{e}}=203, p>.10\right]$.

\section{Discussion}

We carried out Experiment 1 to examine whether or not distractor inhibition can be observed in a parallel visual search task (under display conditions that closely matched those used by Müller \& von Mühlenen, 2000). To do so, we introduced in Experiment 1 a passive-viewing baseline condition that was designed to provide a measure of visual interference between the search array and the detection probe stimuli, uncontaminated by any factors associated with the requirement to "search" for a target.

The passive-viewing condition showed that visual interference was least in the display-on condition, intermediate in the part-off condition, and greatest in the display-off condition (Figure 2). Furthermore, on-probe RTs exhibited a significant effect of the display change condition, but not off-probe RTs, suggesting that the greater interference in the part-off and display-off conditions was due to factors spatially confined to the location of the on-probe stimulus. The likely cause of the interference in the display-on condition is masking by the sustained display stimulus on the detection probe presented superimposed on that stimulus. The greater on-probe costs in the part-off and display-off conditions can be attributed to the abrupt offset of a stimulus part (part off) or the whole stimulus (display off) interfering with the detection of the abrupt onset of the probe stimulus. This added interference may arise within the transient visual system (e.g., Breitmeyer \& Ganz, 1976), or it might arise due to the offset cue (signaling the imminent presentation of the response-relevant stimulus) and the onset target being conceptually similar (see, e.g., Folk, Remington, \& Johnston, 1992; Folk, Remington, \& Wright, 1994). The fact that the interference is local (not affecting responses to off-probes distant from display array stimuli) would argue in favor of the transient system account.

One problem with Experiment 1 (R. M. Klein, personal communication, May 28, 2006) might be that the number of off-probe locations was larger than the number of on-probe locations. Given that a probe could appear with the same probability at either an empty (off-probe) or a stimulus (on-probe) location, the stimulus array may have served as an informative cue for the (on-) probe stimuli, in particular, when display size was small (i.e., with twoand six-item displays). Such "cuing" effects by the search array might have been less strong in the parallel search condition. Under this condition, the observers were occupied with the search and probe detection tasks and may, therefore, have been less aware of this relationship-in contrast to the passive-viewing condition, in which the observers' only task was to discern the presence of the probe. Thus, it is possible that the larger on-probe RT costs (i.e., on-probe RT minus off-probe RT) in the parallel search condition of Experiment 1 reflect a relative decrease of the on-probe RTs in the passive-viewing condition.

To account for any effects resulting from the strategic use of search item locations on on-probe RTs, we carried out a control experiment in which the number of on-probe locations was the same as the number of off-probe locations. We achieved this by presenting, on each trial, a constant number of 10 search stimuli at 10 randomly chosen (out of 20 possible) item locations. On $50 \%$ of all trials, a probe was presented at a distractor, a target, or an empty stimulus location. In this control experiment, the same 12 observers ( 8 of them female; age range, 19-31 years) performed in both the parallel search and the passive-viewing conditions. All of the observers performed first in the passiveviewing and second in the parallel search condition, to avoid carryover of an active search set from the parallel search to the passive-viewing task.

We analyzed probe RTs on target-absent trials using an ANOVA with task (parallel search, passive viewing) and probe (on, off) as factors. This ANOVA revealed a marginally significant effect of task $[F(1,11)=4.51$, $\left.M S_{\mathrm{e}}=18,917, p=.057\right]$ and a significant effect of probe $\left[F(1,11)=46.69, M S_{\mathrm{e}}=2,010, p<.01\right]$. Importantly, the task $\times$ probe interaction was significant $[F(1,11)=10.79$, $\left.M S_{\mathrm{e}}=702, p<.01\right]$. Although on-probe RTs were overall slower than off-probe RTs (522 vs. 433 msec, respectively; main effect of probe), this difference was more pronounced in the parallel search task (on-probe vs. off-probe RTs: 576 vs. $463 \mathrm{msec}$ ) than in the passive-viewing task (on-probe vs. off-probe RTs: 467 vs. $404 \mathrm{msec}$ ). This pattern means that the higher on-probe RT costs in the parallel search relative to the passive-viewing condition of Experiment 1 
were due to distractor inhibition, over and above any cuing effects resulting from the search item locations.

Another important finding emerged in Experiment 1 when we compared physically identical display conditions between the passive-viewing and the parallel search conditions. Although the on-probe costs were 30 to $44 \mathrm{msec}$ greater in the part-off and display-on conditions of the parallel search condition, relative to equivalent display conditions in the passive-viewing condition, there was no differential on-probe cost for the display-off condition $(-5 \mathrm{msec})$. This suggests that (1) there is inhibition of distractor stimuli when the search array is in view at the time the detection probe is presented (superimposed on a distractor), and (2) the inhibition is canceled by the rapid offset of the search stimuli prior to the presentation of the detection probe (in which case, the total on-probe cost can be attributed to visual interference in the transient system).

Two important questions arise from this pattern of results: Why would there be inhibition of the search distractors in Experiment 1, given that a detection probe was equally likely to appear at all (occupied as well as empty) display locations, and at what time does the inhibition arise? Since the inhibition was completely reset when the search display stimuli were extinguished prior to the probe presentation (display-off condition), it is reasonable to conclude that the inhibition does not originate in the probe detection task. This leaves two possibilities: Either the inhibition arises at the point at which observers switch from the search task to the probe detection task (i.e., the inhibition results from the requirement to switch tasks), or it is associated with observers making a "targetpresent"/“target-absent" decision-which involves "rejection" of the search array stimuli, at least of the distractors (e.g., Duncan \& Humphreys, 1989; Humphreys \& Müller, 1993; Müller, Humphreys, \& Donnelly, 1994). According to the second alternative, inhibition is a spatially parallel process of distractor suppression accompanying the selection of a search task response.

If the latter account is correct, there should be inhibition only of the search distractor stimuli, but not of the target, which may receive facilitation. By contrast, the first account would predict that the target is inhibited as well as the distractors. To decide between these alternatives, we analyzed the probe RT in the search task of Experiment 1 for the displayoff, part-off, and display-on conditions according to whether the detection on-probe appeared at the target location (search target-present trials only). The results were consistent with the "distractor suppression" account (see columns 4-6 in Table 1). In all display conditions, targets showed no on-probe RT cost at all (display off, $-23 \mathrm{msec}$; part off, $-13 \mathrm{msec}$; display on, $-32 \mathrm{msec}$ ). This means that responding to on-probes at target locations was facilitated relative to the passive-viewing condition (even for the part-off condition). In summary, all display conditions exhibited facilitation for on-target probes (of some 10-30 msec), whereas only the display-on and part-off conditions, but not the display-off condition, showed inhibition for on-distractor probes. This dissociation indicates that facilitation and inhibition arise from separate causes (considered below).

\section{EXPERIMENT 2}

Caution is indicated in interpreting this finding, however, because distractor inhibition in the display-on and part-off conditions of Experiment 1 may have been due to observers' fixating the target at the end of the search tasks. Similar arguments would apply to the study of Cepeda et al. (1998), who did not control for eye movements. We therefore carried out Experiment 2 to replicate this finding while controlling for eye movements.

Part of the "distractor inhibition" in the previous partoff and display-on conditions may be attributable to eye movements to the target or any other search display stimulus. If an eye movement was made to, say, the target, fixation was displaced from the most "informative" location in the display, the center. On the one hand, this could have led to faster detection of on-target probes relative to offprobes (i.e., target facilitation). On the other hand, making an eye movement away from the center would also have increased the average distance of the search stimuli from fixation. Because, in Experiment 1, there were fewer on-probe locations $(2,6$, and 10 for 2-, 6-, and 10-item displays, respectively) than off-probe ones $(34,30$, and 26), this, in turn, may have impeded the detection of ondistractor stimuli more than that of off-probe stimuli. Thus, eye movements in Experiment 1 may have inflated the on-probe costs observed in the parallel search condition for on-probe and part-off displays, relative to equivalent display conditions for passive viewing, in which there was no need to make eye movements. In fact, given that the display center was the optimal location for detecting probe stimuli, it would have been counterproductive for observers to make eye movements in the passive-viewing condition.

Thus, Experiment 2 was intended to examine whether, and to what extent, inhibition and facilitation would be observed under display conditions similar to those in Experiment 1 , when eye movements were eliminated.

Experiment 2 consisted of two blocked conditions: search display on and search display off, similar to the display-on and display-off search conditions of Experiment 1 . We fixed display size at six stimuli in order to reduce the total number of trials. The observers were presented with a fixation marker cross in the display center and were told to avoid making eye movements during a trial. In the parallel search condition, all of the stimuli were identical, except the target (if present), which was rotated by $45^{\circ}$. The display conditions in the passive-viewing task were identical to those in the parallel search condition, with the exception that all of the stimuli had the same orientation and the observers only had to view the display.

\section{Method}

Participants. A total of 10 unpracticed observers (4 of them male) took part in Experiment 2, with ages ranging from 18 to 38 years. They performed in the parallel search and passive-viewing conditions on separate days.

Apparatus and Stimuli. We presented no search array or probe stimuli within the central four locations of the $6 \times 6$ matrix defining display locations (so stimuli were at least $2.45^{\circ}$ distant from fixa- 
tion). We did this to ensure that the stimuli appeared in extrafoveal vision even on trials on which slow drifts of fixation in the direction of the search target occurred (these are difficult to suppress; see, e.g., Appendix B of Müller \& Findlay, 1987). We monitored eye movements using a Skalar Medical Iris limbus tracker.

Design and Procedure. Both the parallel search and the passiveviewing conditions consisted of two blocked conditions: display on and display off. We counterbalanced the orders of task (parallel search, passive viewing) and display change (display on, display off) conditions across observers. In the parallel search condition, each display change condition consisted of eight blocks of 60 trials, giving 480 trials total (no-probe trials, 2 search target-absent or target-present $\times 120$ trials; probe trials, 2 search target-present or target-absent $\times 2$ on- or off-probe $\times 60$ trials). On search targetpresent trials, 1/6 of on-probes appeared at the target location and $5 / 6$ at one of the distractor locations. When observers had to passively view, rather than actively search, the monitor, each display condition consisted of 240 trials (four blocks of 60 trials), with 120 no-probe and 120 probe trials. The observers were instructed not to make eye movements between the onset of the fixation cross at the start of a trial and a computer-generated "bleep" at the end. The bleep occurred immediately after the detection response on probe trials or 1,000 msec after the search target ("absent"/"present") response on catch trials. Trials on which a saccadic eye movement was detected were rejected online and rerun later at a random point in the trial block. Eye movements were classified as saccades if their amplitude was larger than $1^{\circ}$ and their speed exceeded $35^{\circ} / \mathrm{sec}$. The percentage of rejected trials was $2.1 \%$ in the parallel search and $2.7 \%$ in the passive-viewing condition of Experiment 2.

\section{Results}

Search performance. The group mean target-present and target-absent RTs were 537 and $581 \mathrm{msec}$, respectively. (There was little difference between the display-on and display-off conditions.) The overall error rate was $3.4 \%$, with target misses (4.3\%) more frequent than false alarms (2.5\%).

Probe detection performance. Table 2 presents the on-probe RT costs (on-probe RT minus off-probe RT) for the on-distractor probe (target-absent trials only) and on-target probe (target-present trials only) conditions in the parallel search and passive-viewing conditions. Also listed are the relative RT costs for on-distractor probes and on-target probes in comparison with the on-probe cost in the passive-viewing condition, and the resulting distractor inhibition (target facilitation).

As can be seen from Table 2, the on-distractor probe cost in the parallel search condition was near equivalent to that in the passive-viewing condition for the displayoff condition ( $55 \mathrm{vs.} 48 \mathrm{msec}$ ), but was greater for the display-on condition (54 vs. $28 \mathrm{msec}$ ). In other words, there was "inhibition" in the display-on condition (over and above any visual interference effects estimated in the baseline display-on condition) but no inhibition in the display-off condition. This pattern agrees with the previous Experiment 1. However, the amount of inhibition in the display-on condition was only $26 \mathrm{msec}$, in comparison with $44 \mathrm{msec}$ in the display-on condition of Experiment 1. Although reduced, an ANOVA on the probe RTs (targetabsent trials only) with the factors task (parallel search, passive viewing), probe (off-probe, on-distractor probe), and display change (on, off) revealed a marginally significant three-way interaction $\left[F(1,9)=4.65, M S_{\mathrm{e}}=89, p=\right.$ .06]. A planned (one-tailed) $t$ test comparing the on-probe RT costs for the display-on condition in the parallel search and passive-viewing conditions was significant $[t(9)=$ $2.13, p<.05]$.

In contrast, whereas only the display-on condition, but not the display-off condition, showed distractor inhibition, both conditions showed evidence for target facilitation. That is, the target on-probe cost in the parallel search condition was reliably smaller than the corresponding baseline cost, in both display conditions (display off, 30 vs. $48 \mathrm{msec}$; display on, 14 vs. $27 \mathrm{msec}$ ). We confirmed this using an ANOVA of the probe RTs (target-present trials only), which revealed the task $\times$ probe interaction to be

Table 2

Group Mean Correct Reaction Times (RTs, in Milliseconds) in the Parallel Search Condition to On-Distractor and Off-Probes (Columns 2 and 3; Target-Absent Trials Only), to On-Distractor, On-Target-, and Off-Probes (Columns 4 and 5; Target-Present Trials Only), and to On-Distractor and Off-Probes in the Passive-Viewing Condition (Columns 6 and 7), Separately for the Display Change Conditions (Display Off, Display On) in Experiment 2, With the RT Differences Between On- and Off-Probes (OnProbe RT Cost: On-Off) for the Parallel Search and Passive-Viewing Tasks

\begin{tabular}{|c|c|c|c|c|c|c|}
\hline \multirow[b]{3}{*}{ Display Change } & \multicolumn{6}{|c|}{ Search Condition } \\
\hline & \multicolumn{2}{|c|}{$\begin{array}{c}\text { Parallel } \\
\text { Search-Absent }\end{array}$} & \multicolumn{2}{|c|}{$\begin{array}{c}\text { Parallel } \\
\text { Search-Present }\end{array}$} & \multicolumn{2}{|c|}{$\begin{array}{l}\text { Passive } \\
\text { Viewing }\end{array}$} \\
\hline & $\overline{\mathrm{On}}$ & Off & $\overline{\text { On }}$ & Off & On & Off \\
\hline \multicolumn{7}{|l|}{ Probe } \\
\hline Off & 375 & 396 & 361 & 386 & 338 & 368 \\
\hline On-distractor & 429 & 451 & 398 & 424 & 365 & 416 \\
\hline On-target & & & 375 & 416 & & \\
\hline On-distractor cost & 54 & 55 & 37 & 38 & 27 & 48 \\
\hline On-target cost & & & 14 & 30 & & \\
\hline Inhibition & 26 & 7 & 10 & -10 & & \\
\hline Facilitation & & & -13 & -18 & & \\
\hline
\end{tabular}

Note-Distractor inhibition and target facilitation are estimated by the differential on-probe RT costs between corresponding parallel search and passive-viewing conditions. 
significant $\left[F(1,9)=7.39, M S_{\mathrm{e}}=418, p<.05\right]$. However, the task $\times$ probe $\times$ display change interaction was nonsignificant $\left[F(1,9)=0.06, M S_{\mathrm{e}}=400, p=.82\right]$, indicating equal facilitation in the display-on and display-off conditions of the parallel search, relative to the passiveviewing condition. Similar to the reduction in distractor inhibition when eye movements were controlled, the amount of facilitation was also reduced in comparison with Experiment 1 (16 vs. $27 \mathrm{msec}$; data combined for the display-on and display-off conditions of Experiments 1 and 2 , respectively).

\section{Discussion}

In summary, the display-on condition, but not the displayoff condition, showed evidence of distractor inhibition (of $26 \mathrm{msec}$ ). In contrast, both display change conditions showed evidence of target facilitation of, on average, $16 \mathrm{msec}$. The inhibition and facilitation in Experiment 2 were only about half of that observed in Experiment 1, suggesting that the effects observed previously were inflated by eye movements (e.g., to the target location). However, the fact that the effects remained significant and exhibited the same pattern in Experiment 2 as in the previous experiment argues that facilitation and, in particular, inhibition are not simply an eye movement artifact. The facilitation is probably caused by the search target location's being covertly attended at the time the probe is presented, regardless of whether or not the target remained visible. However, inhibition is observed only when the distractors remain visible, not when they are removed. This argues against inhibition's being coded in spatial coordinates, a point we will consider further in the General Discussion.

\section{EXPERIMENT 3}

In the display-off condition of Experiment 1, abrupt luminance decrements at distractor locations reduced the inhibition almost instantly (i.e., within $60 \mathrm{msec}$, the time between the decrement and the onset of the probe stimulus). Furthermore, the degree to which inhibition was reduced depended on the amount of luminance change at an inhibited location: It was less when only a stimulus part was removed (part-off condition) than when the whole stimulus was extinguished (display-off condition), in which case the inhibition was completely reset.

This finding qualifies Yantis and Hillstrom's (1994) proposal that changes in "old" objects do not capture attention. Yantis and Hillstrom may be right in arguing that the removal of a part of an old stimulus may not itself attract attention. However, it may reset the status of that stimulus by reducing its inhibition, so that a subsequent salient change at its location can more readily capture attention. This account presupposes that the abrupt removal of parts of distractor stimuli reduces the inhibition locally (i.e., only for distractors that were subject to a change), rather than globally, for all distractors, regardless of whether or not they underwent a change (i.e., the removal of parts of some stimuli generates a global signal resetting the status of all inhibited stimuli). In contrast, given Yantis and Johnson's (1990) demonstration that visual attention has a limited number of about four "priority tags" available to be allocated to salient luminance changes, the reduced on-probe RT costs in the part-off relative to the display-on condition of Experiment 1 may also reflect attentional priority of processing for part-offset (i.e., changed) distractors, rather than reduced distractor inhibition.

In particular, Yantis and Johnson (1990) assumed that the visual attention system can prioritize processing for up to four items marked by (simultaneous) abrupt visual onsets, that priority tags are allocated in parallel to abruptonset items, and that tagged items will be processed prior to untagged items (with untagged abrupt-onset items having the same, reduced priority as no-onset items). The evidence for this account came from a serial visual search study in which the ratio of abrupt-onset to no-onset items was systematically varied. It was found that (1) the search RTs were, on average, faster for abrupt-onset items than for no-onset items; (2) for onset targets, the function relating search RT to the number of abrupt-onset items at first exhibited a shallow increase up to four items, whereas the function for no-onset items showed a steep increase; and (3) thereafter, the two functions exhibited equivalent increases. This pattern is as predicted if the attention system has a limited number of four priority tags available. (If there are more than four changed items, tags are assigned on a competitive basis, yielding, on average, greater inhibition.)

However, in the part-off condition of Experiment 1, all of the stimulus changes were global - that is, occurring at all stimulus locations at the same time. Thus, Experiment 1 does not permit distinguishing between whether luminance decrements affect distractor inhibition locally or globally and, associated with this, whether the abrupt luminance decrements lead to reduced distractor inhibition or, alternatively, prioritized processing of (part-offset) distractors.

We therefore carried out Experiment 3 using a logic adopted from Yantis and Johnson (1990): systematic variation of the ratio of changed (part-off) to unchanged distractors, in order to examine whether the smaller on-probe RT costs for changed distractors in the present paradigm reflect reduced inhibition rather than the priority of processing assigned to them.

\section{Method}

Participants. A total of 10 new and unpracticed observers ( 5 men; ages ranging from 21 to 29 years), with normal or correctedto-normal vision, took part in Experiment 3.

Stimuli. The displays consisted of a fixed number of 10 search array stimuli, which could be followed by a (luminance increment) detection probe superimposed on the search stimuli. After the search task response ("present"/“absent"), or 400-800 msec following display onset, in the passive-viewing condition, the internal corner junctions of 2, 4, or 8 distractors were extinguished. Thus, the stimulus conditions in Experiment 3 matched those of the part-off condition in Experiment 1, except that the disappearance of the number of internal L-junctions was varied systematically.

Design and Procedure. The search condition consisted of 960 experimental trials (target [present, absent] $\times$ distractor change $[2,4,8$ items $] \times 160$ trials). On half of the trials (480 trials total), the search task response triggered the presentation of a luminance increment probe. Half of these stimuli were off-probes, and half were on-probes (240 trials each). The on-probe was equally likely 
to be presented at each stimulus location. Thus, in the 2-, 4-, and 8 -distractor change conditions, there were 16, 32, and, 64 trials, respectively, with probes appearing on changed distractors, and 64 , 48 , and, 16 trials, respectively, with probes appearing on unchanged distractors. Across the three distractor change conditions, in $10 \%$ of the on-probe trials ( 24 trials total), the probe was presented at the target location. We did not subject such trials to further analysis. The passive-viewing condition consisted of 960 trials (distractor change $[2,4,8$ items $] \times 320$ trials $)$. On half $(480)$ of the trials, a probe stimulus was presented, with $50 \%$ being off-probes and $50 \%$ on-probes (240 trials each). On-probes were presented according to the ratio of changed to unchanged distractors in a given distractor change condition, analogously to the search task. In both tasks, all trial types were presented in randomized order. Overall, the parallel search and the passive-viewing conditions consisted of 12 blocks each (with 5 warming-up trials plus 80 experimental trials per block).

Observers performed in the parallel search and passive-viewing conditions on 2 consecutive days, with order counterbalanced across observers. At the beginning of each search condition, observers practiced the experimental task for $20 \mathrm{~min}$.

\section{Results}

Search performance. Target-present RTs were faster than target-absent RTs (613 vs. $633 \mathrm{msec}$ ), and target misses were slightly less frequent than false alarms $(3.4 \%$ vs. $4.6 \%$ ).

Probe detection performance. We examined probe RTs for evidence of distractor inhibition only on targetabsent search trials. The first three rows of Table 3 present the mean probe RTs as a function of distractor change, separately for off-probes, probes on changed distractors, and probes on unchanged distractors. Columns 1-3 and columns 4-6 give the probe RTs following the parallel search task and the passive-viewing task, respectively.

An ANOVA of the probe RTs, with the factors of task (parallel search, passive viewing), distractor change (2, 4, 8 items), and probe (off-probe, probe on changed location, probe on unchanged location) revealed significant main effects of task $\left[F(1,9)=10.28, M S_{\mathrm{e}}=10,755, p<\right.$
Table 3

Group Mean RTs (in Milliseconds) on Target-Absent Trials of the Search Task (Columns 1-3) and Passive-Viewing Task (Columns 4-6) to Off-Probes, to Probes On-Changed, and

Probes On-Unchanged Distractors As a Function of Distractor Change $(2,4,8)$ in Experiment 3 with the RT Differences

Between On- and Off-Probes (On-Probe RT Cost: On-Off) for the Parallel Search and Passive-Viewing Tasks

\begin{tabular}{|c|c|c|c|c|c|c|}
\hline \multirow[b]{2}{*}{ Distractor Change } & \multicolumn{3}{|c|}{ Parallel Search } & \multicolumn{3}{|c|}{ Passive Viewing } \\
\hline & 2 & 4 & 8 & 2 & 4 & 8 \\
\hline \multicolumn{7}{|l|}{ Probe } \\
\hline Off & 354 & 345 & 350 & 332 & 337 & 326 \\
\hline On-changed distractors & 443 & 417 & 420 & 381 & 384 & 371 \\
\hline On-unchanged distractors & 479 & 462 & 469 & 381 & 396 & 385 \\
\hline \multicolumn{7}{|l|}{ On-Probe RT Cost } \\
\hline Changed distractors & 89 & 73 & 71 & 49 & 47 & 45 \\
\hline Unchanged distractors & 125 & 117 & 119 & 49 & 59 & 59 \\
\hline Distractor Inhibition & & & & & & \\
\hline Changed distractors & 41 & 25 & 26 & & & \\
\hline Unchanged distractors & 77 & 57 & 60 & & & \\
\hline
\end{tabular}

Note-Distractor inhibition is estimated by the differential on-probe RT costs between corresponding search and passive-viewing conditions.

.05$,$] and probe \left[F(2,18)=48.72, M S_{\mathrm{e}}=2,543, p<.001\right]$. Furthermore, the task $\times$ probe interaction was significant $\left[F(2,18)=11.50, M S_{\mathrm{e}}=1,359, p<.01\right]$. The main effect of task occurred because the probe RTs were reduced, overall, in the passive-viewing relative to the parallel search condition (366 in comparison with $415 \mathrm{msec}$ ). The main effect of probe occurred because off-probes were detected faster than probes on changed locations and on unchanged locations (340 vs. 403 and $429 \mathrm{msec}$, respectively). However, as is indicated by the significant interaction, this effect was more pronounced in the parallel search condition (349 vs. 427 and $470 \mathrm{msec}$ ) than in the passive-viewing condition (332 vs. 379 and $388 \mathrm{msec}$ ).

To further explore the effects of distractor change, we examined the on-probe RT costs using another ANOVA,
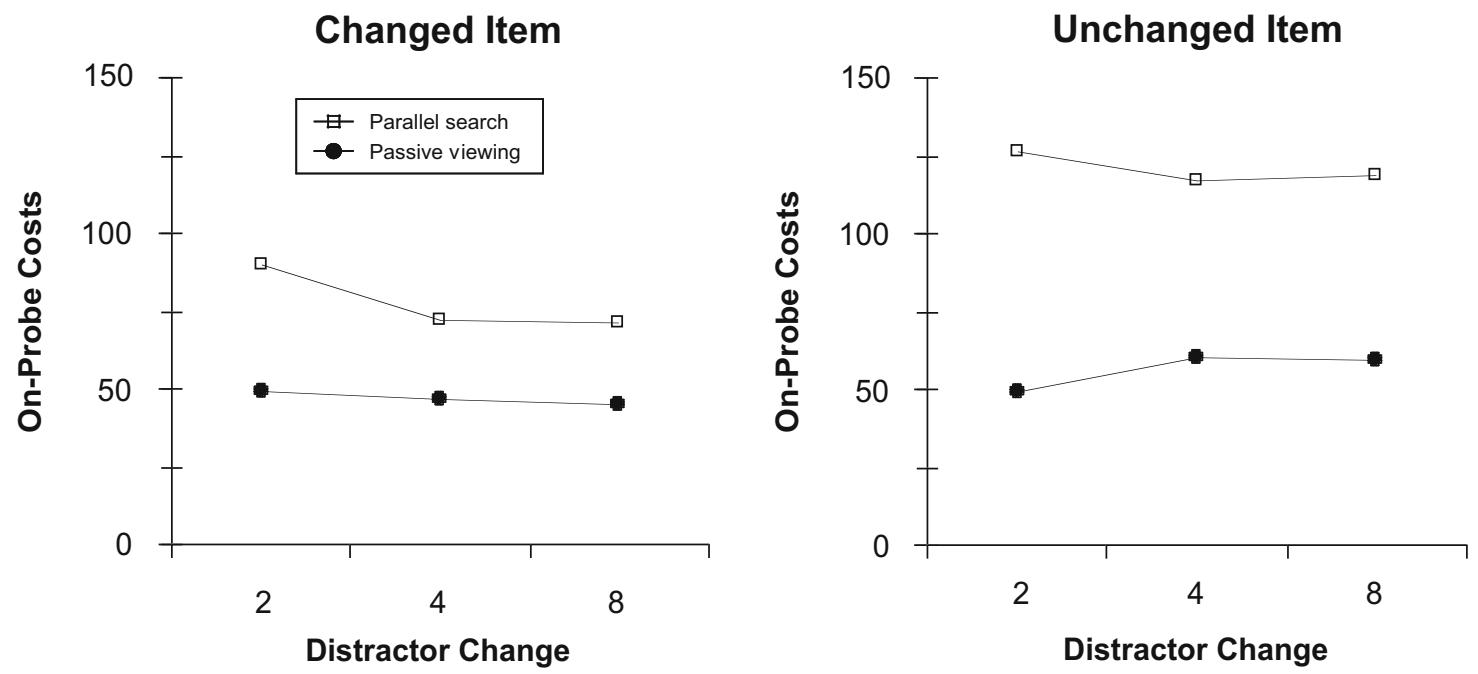

Figure 4. Experiment 3: Reaction time (RT) differences (in milliseconds) between the on- and off-probes (on-probe RT cost) in the parallel search condition (squares) and the passive-viewing condition (circles), separately according to whether two, four, or eight items were changed prior to the probe presentation. The left-hand and right-hand panels present the on-probe RT costs for probes presented at the locations of changed and unchanged items, respectively. 
with the factors of task (parallel search, passive viewing), distractor change (two, four, eight items), and probe (changed location, unchanged location). This ANOVA also revealed a significant interaction between task and probe $\left[F(1,9)=6.48, M S_{\mathrm{e}}=1,344, p<.05\right]$. As can be seen from Figure 4, which presents on-probe costs for changed (left graph) and for unchanged (right graph) distractors, on-probe RT costs were more pronounced in the parallel search (78 vs. $121 \mathrm{msec})$ than in the passive-viewing condition (47 vs. $56 \mathrm{msec}$ ). Most importantly, in this ANOVA, no effects involving distractor change reached significance (all $p s>.15$ ). This provides evidence that luminance decrements reduce the inhibition associated with search distractors locally - that is, only for stimuli that were subject to a change. In addition, distractor inhibition was independent of the number of changed distractors (see Figure 5); in particular, inhibition was not reduced with two in comparison with eight changed distractors in the display. This argues against an explanation of the reduced RT disadvantages for changed relative to unchanged distractors in terms of the attentional priority account (Donk \& Theeuwes, 2001; Yantis \& Johnson, 1990).

\section{Discussion}

We designed Experiment 3 to measure RT costs for onprobes relative to off-probes under conditions in which the internal parts of either two, four, or eight distractor stimuli were removed (while those of eight, six, or two remained on). This was intended to account for the reduced on-probe RT costs observed in the part-off condition of Experiment 1 in terms of either a local reduction in distractor inhibition or, alternatively, the assignment of attentional priority tags to a limited number of part-offset distractors.

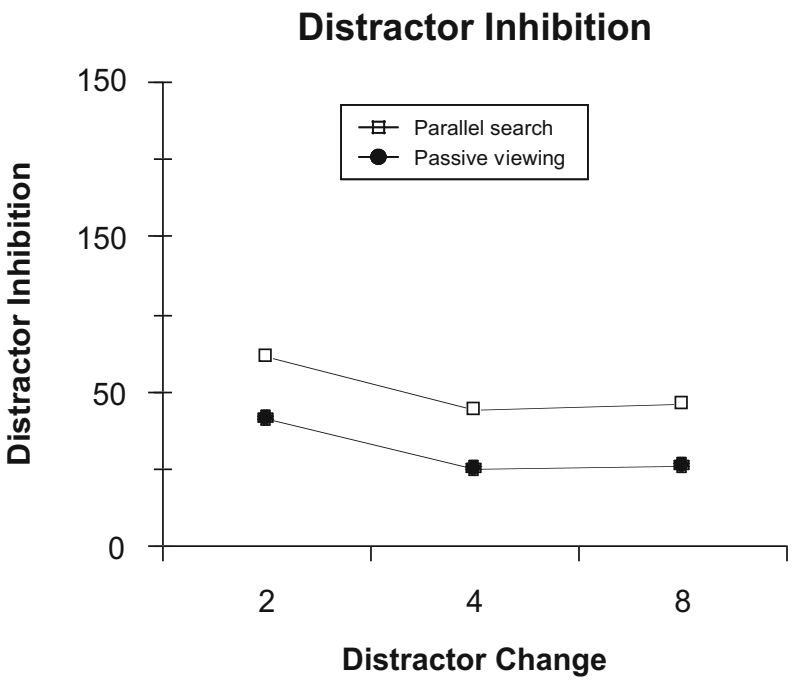

Figure 5. Experiment 3: Differential on-probe reaction time (RT) costs (in milliseconds) between the parallel search and the passive-viewing conditions (distractor inhibition) as a function of distractor change (two, four, or eight items), separately for probes presented at the locations of changed (squares) and unchanged (circles) items.
Experiment 3 revealed reduced on-probe RT costs for changed in comparison with unchanged distractors (relative to the passive-viewing condition), replicating the finding of Experiment 1. However, the data of Experiment 3 argue against this reduced on-probe RT cost being due to priority of (attentional) processing assigned to changed search stimuli (cf. Yantis \& Johnson, 1990): At variance with the prediction of this account, there was no evidence of differential magnitudes of distractor inhibition when 2 (i.e., $<4$ ), 4 , or 8 (i.e., $>4$ ) search distractors were changed. This indicates that distractor inhibition can be characterized as a local phenomenon, affecting all search stimuli of a particular type in an equal and spatially parallel manner.

\section{GENERAL DISCUSSION}

\section{Distractor Inhibition in Parallel Visual Search}

The present experiments provided new evidence for distractor inhibition's operating in parallel visual search. The passive-viewing condition of Experiment 1 required observers only to note the presence of stimuli (without actively searching through them) when, similar to the parallel search condition, the search display stimuli were completely removed (display off) or remained in view (display on) or the internal L-junctions of the search stimuli were extinguished (part off) prior to probe presentation. The results were (1) no differential on-probe RT costs between the two task conditions (passive viewing, parallel search) when the display stimuli were turned off before the presentation of the detection probe, but (2) an increased on-probe RT cost of 30-40 msec in the parallel search condition (over and above any cost attributable to visual interference) when the detection probe was presented superimposed on a distractor stimulus that remained on (wholly or in part) after the search task response. The second point can be taken as evidence for distractor inhibition in parallel visual search.

Furthermore, the pattern of effects revealed in Experiment 1 throws light on the time at which the distractor inhibition arises and the function it serves in visual search. There was no evidence of any inhibition when the display stimuli were not to be searched, so the inhibition does not originate in the probe detection task. In addition, inhibition affected RTs only to on-distractor probes, but not to on-target probes (which showed facilitation). This suggests that inhibition is associated with the search targetpresent/target-absent decision - which involves "rejection" of the search array distractors (e.g., Duncan \& Humphreys, 1989; Humphreys \& Müller, 1993; Müller et al., 1994). Furthermore, distractor inhibition was dependent on the distractors' remaining in view, in contrast to target facilitation (which was evident regardless of whether or not the target remained visible).

Distractor inhibition was still evident in Experiment 2, in which observers were prevented from making eye movements (though the distractor inhibition was halved in magnitude in the search condition of Experiment 2). Likewise, the effect of target facilitation was replicated in Experiment 2 (though it was also reduced in magnitude when eye movements were eliminated). 
Since there was a reduction in distractor inhibition in Experiment 1 for the part-off relative to the display-on condition, in Experiment 3, we systematically varied the number of changed distractors (while keeping the total number of stimuli constant): two, four, or eight. This variation had no differential impact on distractor inhibition, consistent with the (distractor) changes' reducing the distractor inhibition locally. (A differential impact would have been consistent with attentional prioritization of changed distractors.)

Several conclusions can be drawn from this pattern of effects. (1) There is inhibition of search distractors when the stimuli are visible at the time the detection probe is presented superimposed on a distractor. (2) The inhibition affects all distractors of a particular type simultaneously. It is found at randomly selected distractor locations, regardless of whether a target was present or absent. (3) The inhibition is attentional, top down, in nature. It depends on the relevance of the display stimuli for the observer's task: There is no inhibition when the stimuli are not to be searched. (4) The inhibition is canceled by the abrupt offset of the search stimuli prior to the presentation of the detection probe; if this occurs, the total on-probe RT cost can be attributed to visual interference in the transient visual system. (5) The inhibition is reduced by part offsets (changes) of display elements. This reduction is local; that is, it affects all changed distractors in an equal and spatially parallel manner. (6) The distractor inhibition is object based, observed only when the search stimuli are in view at the onset of the detection probe. The target facilitation, by contrast, is location based, observed regardless of whether or not the target remains in view.

\section{Relations to Previous Studies of Distractor Inhibition in Parallel Visual Search}

The search distractor inhibition demonstrated in the present experiments appears in many ways similar to the inhibitory effect described by Cave and his colleagues (e.g., Cepeda et al., 1998; Kim \& Cave, 1999). However, the present experiments introduced several methodological variations, which permit a clearer understanding of the nature of distractor inhibition in parallel visual search. The first variation concerns the order of tasks: In the study of Cepeda et al., the observers first responded to the probe and only then to the (previously presented) search target. We reversed this order in the present study, to do away with the need to actively maintain a memory of the search display into the probe detection task. In the study of Cepeda et al., this active-maintenance requirement was, arguably, crucial for their finding of distractor inhibition. Evidence for this is provided by the present finding that, in contrast to Cepeda et al., inhibition of distractor locations was not observed when the search stimuli were removed prior to the presentation of the detection probe. Thus, distractor inhibition is manifest only when the search display remains in view (as in the present study) or when observers maintain a memory representation of the search display (as in Cepeda et al., 1998). This argues that distractor inhibition is object based (rather than simply location based), tied to either a direct "visual" or an indirect "memory" representation of the search distractors.

The second major difference concerns the fact that Cepeda et al. (1998) used a very simple, geometrically regular layout of a fixed number of search display stimuli (4 items equidistantly arranged on the circumference of a circle). In contrast, the present study used random, irregular display arrangements, and the number of stimuli was variable, up to 10 items. These changes were introduced because Geyer et al. (2007) have shown that crosstrial inhibitory priming effects depend on regular layout of a very limited number of stimuli (3 or 4). Geyer et al. took this to suggest that observers use a rigid geometrical (mental) frame to place inhibitory tags at nontarget locations. These effects carry over into the next search trial because the new display is "seen" as a simple (rotational) transformation of the previous display (i.e., the mental frame is rotated, by a certain amount, around the virtual circle centered at fixation, maintaining its basic geometrical structure). By ruling out such a strategy in the present experiments, the results show two things: Distractor inhibition in parallel visual search is not limited to small numbers of regularly arranged distractors but is also evident with large numbers of irregularly arranged stimuli. Furthermore, given that the inhibitory effect was completely reset by the removal of the search display when no enduring mental representation of the display could be formed (due to the large number of irregularly placed stimuli), parallel distractor inhibition in visual search is a "within-trial effect" (cf. Shore \& Klein, 2000), rather than a "cross-trial effect" based on some enduring memory of the search display.

Two further points are worth mentioning. First, the present experiments focused on the examination of distractor inhibition on search target-absent trials. Given that inhibition was manifest even under this condition, the effect is not dependent on target selection. Since there were no target-absent trials in the task of Cepeda et al. (1998), this possibility could not be ruled out on the basis of their findings. Second, given that there was reliable distractor inhibition when it was probed after observers had responded "target-present" or "target-absent," this result may be best explained by assuming that the inhibition is associated with response selection in the search task. This is another point that could not be made on the basis of Cepeda et al.'s findings.

\section{Relations to Visual Marking}

The distractor inhibition demonstrated in the present study is in several respects similar to the "visual marking" effect first described by Watson and Humphreys (1997; see also Humphreys, Watson, \& Jolicœur, 2002; Olivers \& Humphreys, 2002; Watson \& Humphreys, 1998, 2000; for a review, see Watson, Humphreys, \& Olivers, 2004). Watson and Humphreys conceive of visual marking as a topdown mechanism facilitating the search of new elements in the visual field, via the inhibitory marking of old items. In their original demonstration, observers searched for a conjunctively defined target under three conditions: (1) a 
standard conjunction search condition, in which observers had to discern the presence of a blue " $\mathrm{H}$ " target among heterogeneous blue "A" and green " $\mathrm{H}$ " distractors; (2) a feature search condition, in which the blue " $\mathrm{H}$ " target appeared among homogeneous blue "A" distractors; and (3) a "preview condition," in which one set of distractors, green "H"s (preview set), was displayed for $1 \mathrm{sec}$ prior to the presentation of the second set, blue "A"s, along with the blue " $\mathrm{H}$ " target (target set). The critical finding was that, in the preview condition, target detection was more efficient than in standard conjunction search and almost as efficient as in feature search. Subsequent studies have confirmed the preview effect for a variety of search stimuli.

The present distractor inhibition effect resembles visual marking in at least two respects. The first is the time course of visual marking, which, according to Watson and Humphreys (1997), takes some $400 \mathrm{msec}$ to become fully effectual. In the present experiments, the observers may have had a similar length of time to inhibit the search distractors. (Recall that probe stimulus presentation followed $60 \mathrm{msec}$ after the overt search task response, which itself involved time-consuming motor preparation processes prior to the overt response.) Second, Watson and Humphreys (1997) reported that visual marking was abolished in their preview condition when abrupt luminance changes - increments or decrements - occurred at the initial distractor locations at the same time as the new stimuli were presented. This compares with the present experiments, in which abrupt luminance decrements at inhibited locations reduced the inhibition almost instantly (i.e., within $60 \mathrm{msec}$, the time between the decrement and the onset of the probe stimulus).

However, there also appear to be dissimilarities between visual marking and the present distractor inhibition effect. First, whereas visual marking is classically observed in "serial" (conjunction) search, distractor inhibition was observed in "parallel" (feature) search. Thus, one might consider visual marking as a process involved in "serial" search (see, e.g., Shore \& Klein, 2000) and distractor inhibition as a process in "parallel" search. However, since the preview set distractors are, as a rule, featurally homogeneous (e.g., green "Hs" in Watson \& Humphreys, 1997), a parallel mechanism of distractor inhibition associated with the rejection of the preview set of items may well be at work in the marking paradigm as well. A second difference is that, in the present experiments, the observers had no incentive to inhibit the distractors, because, following the search task response, a detection probe could appear at all (occupied and unoccupied) display locations. In contrast, in the preview paradigm, the observers have an explicit incentive to (voluntarily) suppress the previewed distractors, because they know that the target, if present, will be among the second set of items. However, over the course of practice, inhibitory marking of preview set distractors may become automatized, perhaps reducing the amount of top-down suppressive control to a level similar to that in the present task. Consequently, the differential incentive to inhibit distractors between the two paradigms does not conclusively argue against the same (voluntary/ automatic) mechanisms being at work. Third, one may argue that visual marking and distractor inhibition serve different functions: Whereas visual marking is associated with the prioritization of new elements due to the deprioritization of old elements, distractor inhibition in the present experiments is associated with response selection. However, these functions may not be mutually exclusive. Rather, deprioritization of the preview set items may involve a first, albeit implicit, (response) decision - namely, to reject a set of items from further search-for example, as envisaged in Humphreys and Müller's (1993) "search via recursive rejection" (SERR) model of visual search. ${ }^{5}$ Finally, Watson and Humphreys (1997) failed to find a preview effect when the onset of the target set items was accompanied by transient luminance changes at the locations of the old distractors - which led them to conclude that the visual marking is spatially coded. Thus, one might propose that visual marking and distractor inhibition differ with regard to the representations that underlie the two effects: location-based versus object-based inhibition. However, since the preview set of items typically remains in view when the target set is presented, it cannot be ruled out on the basis of Watson and Humphreys's (1997) findings that the inhibitory tags are associated with the distractor objects, which continue to be present at particular locations (see also note 5).

In summary, further work is required to examine the relation of the distractor inhibition effect demonstrated in the present study to visual marking (which itself may involve multiple mechanisms). ${ }^{6}$ As it stands, however, the present effect appears to be most consistent with the "classical" account of visual marking as being due to an inhibitory memory template that mediates the attentional suppression of irrelevant (old) items.

\section{AUTHOR NOTE}

This research was supported by Deutsche Forschungsgemeinschaft Grant FOR 480. Correspondence concerning this article should be addressed to T. Geyer, Department of Psychology, Ludwig-MaximiliansUniversität München, Leopoldstrasse 13, 80802 München, Germany (e-mail: geyer@1mu.de).

\section{REFERENCES}

Breitmeyer, B. G., \& GanZ, L. (1976). Implications of sustained and transient channels for theories of visual pattern masking, saccadic suppression, and information processing. Psychological Review, 83, 1-36.

Cepeda, N. J., Cave, K. R., Bichot, N. P., \& Kim, M.-S. (1998). Spatial selection via feature-driven inhibition of distractor locations. Perception \& Psychophysics, 60, 727-746.

Chun, M. M., \& NaKayama, K. (2000). On the functional role of implicit visual memory for the adaptive deployment of attention across scenes. Visual Cognition, 7, 65-81.

Danziger, S., Kingstone, A., \& Snyder, J. (1998). Inhibition of return to successively stimulated locations in a sequential visual search paradigm. Journal of Experimental Psychology: Human Perception \& Performance, 24, 1467-1475.

Donk, M., \& Theeuwes, J. (2001). Visual marking beside the mark: Prioritizing selection by abrupt onsets. Perception \& Psychophysics, 63, 891-900.

DunCan, J., \& Humphreys, G. W. (1989). Visual search and stimulus similarity. Psychological Review, 96, 433-458.

FinLEY, G. (1985). A high-speed point plotter for vision research [Technical note]. Vision Research, 25, 1993-1997.

Folk, C. L., Remington, R. W., \& Johnston, J. C. (1992). Involuntary covert orienting is contingent on attentional control settings. Journal 
of Experimental Psychology: Human Perception \& Performance, 18, 1030-1044.

Folk, C. L., Remington, R. W., \& Wright, J. H. (1994). The structure of attentional control: Contingent attentional capture by apparent motion, abrupt onset, and color. Journal of Experimental Psychology: Human Perception \& Performance, 20, 317-329.

Found, A., \& MüLlER, H. J. (1996). Searching for unknown feature targets on more than one dimension: Investigating a "dimension-weighting" account. Perception \& Psychophysics, 58, 88-101.

Geyer, T., Müller, H. J., \& Krummenacher, J. (2007). Cross-trial priming of element positions in visual pop-out search is dependent on stimulus arrangement. Journal of Experimental Psychology: Human Perception \& Performance, 33, 788-797.

Humphreys, G. W., \& Müller, H. J. (1993). SEarch via Recursive Rejection (SERR): A connectionist model of visual search. Cognitive Psychology, 25, 43-110.

Humphreys, G. W., Watson, D. G., \& Joliceur, P. (2002). Fractionating the preview benefit in search: Dual-task decomposition of visual marking by timing and modality. Journal of Experimental Psychology: Human Perception \& Performance, 28, 640-660.

JIANG, Y., \& WANG, S. W. (2004). What kind of memory supports visual marking? Journal of Experimental Psychology: Human Perception \& Performance, 30, 79-91.

KIM, M.-S., \& CAVE, K. R. (1995). Spatial attention in visual search for features and feature conjunctions. Psychological Science, 6, 376-380.

KIM, M.-S., \& CAVE, K. R. (1999). Top-down and bottom-up attentional control: On the nature of interference from a salient distractor. Perception \& Psychophysics, 61, 1009-1023.

KLEIN, R. [M.] (1988). Inhibitory tagging system facilitates visual search. Nature, 334, 430-431.

Klein, R. M., Munoz, D. P., Dorris, M. C., \& Taylor, T. L. (2001). Inhibition of return in monkey and man. In C. L. Folk \& B. S. Gibson (Eds.), Attraction, distraction, and action: Multiple perspectives on attention capture (pp. 27-47). Amsterdam: Elsevier.

Kumada, T., \& HumphreYs, G. W. (2002). Cross-dimensional interference and cross-trial inhibition. Perception \& Psychophysics, 64, 493-503.

Luck, S. J., \& Vogel, E. K. (1997). The capacity of visual working memory for features or conjunctions. Nature, 390, 279-281.

Maljkovic, V., \& NaKayama, K. (1994). Priming of pop-out: I. Role of features. Memory \& Cognition, 22, 657-672.

Maljkovic, V., \& Nakayama, K. (1996). Priming of pop-out: II. The role of position. Perception \& Psychophysics, 58, 977-991.

MaljKovic, V., \& NaKayama, K. (2000). Priming of pop-out: III. A short-term implicit memory system beneficial for rapid target selection. Visual Cognition, 7, 571-595.

MülleR, H. J., \& Findlay, J. M. (1987). Sensitivity and criterion effects in the spatial cuing of visual attention. Perception \& Psychophysics, 42, 383-399.

Müller, H. J., Humphreys, G. W., \& Donnelly, N. (1994). SEarch via Recursive Rejection (SERR): Visual search for single and dual form-conjunction targets. Journal of Experimental Psychology: Human Perception \& Performance, 20, 235-258.

Müller, H. J., \& von Mühlenen, A. (2000). Probing distractor inhibition in visual search: Inhibition of return. Journal of Experimental Psychology: Human Perception \& Performance, 26, 1591-1605.

Olivers, C. N. L., \& Humphreys, G. W. (2002). When visual marking meets the attentional blink: More evidence for top-down, limitedcapacity inhibition. Journal of Experimental Psychology: Human Perception \& Performance, 28, 22-42.

Olivers, C. N. L., Meijer, F., \& Theeuwes, J. (2006). Feature-based memory-driven attentional capture: Visual working memory content affects visual attention. Journal of Experimental Psychology: Human Perception \& Performance, 32, 1243-1265.

Segalowitz, S. J., \& Graves, R. E. (1990). Suitability of the IBM XT, $\mathrm{AT}$, and PS/2 keyboard, mouse, and game port as response devices in reaction time paradigms. Behavior Research Methods, Instruments, \& Computers, 22, 283-289.

Shore, D. I., \& Klein, R. M. (2000). On the manifestations of memory in visual search. Spatial Vision, 14, 59-75.

Soto, D., \& Humphreys, G. W. (2007). Automatic guidance of visual attention from verbal working memory. Journal of Experimental Psychology: Human Perception \& Performance, 33, 730-757.

Watson, D. G., \& Humphreys, G. W. (1997). Visual marking: Prioritiz- ing selection for new objects by top-down attentional inhibition of old objects. Psychological Review, 104, 90-122.

Watson, D. G., \& Humphreys, G. W. (1998). Visual marking of moving objects: A role for top-down feature-based inhibition in selection. Journal of Experimental Psychology: Human Perception \& Performance, 24, 946-962.

Watson, D. G., \& Humphreys, G. W. (2000). Visual marking: Evidence for inhibition using a probe-dot detection paradigm. Perception \& Psychophysics, 62, 471-481.

Watson, D. G., Humphreys, G. W., \& Olivers, C. (2004). The use of time as well as space in visual selection. In C. Kaernbach, E. Schröger, \& H. J. Müller (Eds.), Psychophysics beyond sensation (pp. 289-309). Hillsdale, NJ: Erlbaum.

Wolfe, J. M., Butcher, S. J., Lee, C., \& Hyle, M. (2003). Changing your mind: On the contributions of top-down and bottom-up guidance in visual search for feature singletons. Journal of Experimental Psychology: Human Perception \& Performance, 29, 483-502.

Yantis, S., \& Hillstrom, A. P. (1994). Stimulus-driven attentional capture: Evidence from equiluminant visual objects. Journal of Experimental Psychology: Human Perception \& Performance, 20, 95-107.

Yantis, S., \& Johnson, D. J. (1990). Mechanisms of attentional priority. Journal of Experimental Psychology: Human Perception \& Performance, 16, 812-825.

YANTIS, S., \& JonidEs, J. (1984). Abrupt visual onsets and selective attention: Evidence from visual search. Journal of Experimental Psychology: Human Perception \& Performance, 10, 601-621.

Zimba, L. D., \& Hughes, H. C. (1987). Distractor-target interactions during directed visual attention. Spatial Vision, 2, 117-149.

\section{NOTES}

1. The positional inhibition effects observed in parallel search are unlikely to be due to IOR (e.g., Klein, Munoz, Dorris, \& Taylor, 2001), for two reasons: First, in visual search for salient feature targets among homogeneous distractors, attentional capture by a distractor (followed by IOR) is rather unlikely. Second, the fact that detection RTs are expedited when the target position is repeated across trials would further argue against IOR's playing a role in parallel visual search (see Maljkovic \& Nakayama, 1996).

2. The presentation of early-detection probes on some trials may have made observers "search" for such stimuli in an active manner, rather than viewing the display passively, as intended. However, this would be expected to diminish, rather than increase, any differences in on-probe RT costs between the passive-viewing and the parallel search conditions, providing a conservative test of the hypothesis.

3. The four-way interaction may be explained by assuming that larger display sizes (i.e., 6- and 10-item displays) afford similarity-based grouping of distractors, enabling their linked rejection from search (e.g., Duncan \& Humphreys, 1989; Humphreys \& Müller, 1993; Müller, Humphreys, \& Donnelly, 1994) — which leads to more robust/enhanced distractor inhibition.

4. Probe RTs are likely to be faster in the part-off condition than in the display-on condition because part-off display changes act as a temporal warning signal, reducing the time taken to switch from the search to the probe detection task. However, full removal of the search items, as in the display-off condition, may also have a harmful effect (e.g., due to enhanced interference arising in the transient visual system), overriding the beneficial (warning signal) effect deriving from the display changes. The latter assumption receives support from the passive-viewing condition, in which probe RTs tended to be longer, overall, in the part-off and display-off conditions (368 and $369 \mathrm{msec}$, respectively) relative to the display-on condition $(348 \mathrm{msec})$.

5. In the SERR model (Humphreys \& Müller, 1993), target and distractor templates compete to determine the search response. The templates are connected to all feature analyzer units coding the target and the distractors and to location units, which code the spatial coordinates of the search stimuli and gate the activity of feature analyzers through to the template units. (Target and distractor templates may receive activation from the same type of analyzers if the target and distractor are featurally similar.) As soon as, say, the target template wins the competition (i.e., as soon as a "target-present" response is selected), all active distractor templates are inhibited, which in turn suppresses all location units except for those supported by activation from target feature analyzers. In this way, distractor inhibition does not affect feature coding as such but, rather, the gating of distractor feature information onto the template units. This 
means that distractor inhibition is object based, in the sense that it operates from short-term memory templates for objects, but space based, in the sense that it acts on location units gating distractor feature information through to the template units. Note that, in SERR, the inhibition of distractor templates is not equivalent to their removal; the removal of inhibited templates would release the inhibition of distractor locations.

6 . Recently, there has been a controversy concerning the mechanisms underlying the preview effect: Is it on the basis of "voluntary" inhibition of the preview set items (Watson, Humphreys, and their colleagues), "automatic" facilitation of the target set items produced by their new onsets (e.g., Donk \& Theeuwes, 2001), temporal segregation of the target set from the preview set items on the basis of their "asynchronous" presentation and subsequent search within the target set (e.g., Jiang \& Wang, 2004), or a combination of the three mechanisms? Whatever the answer, neither the Donk and Theeuwes nor the Jiang and Wang alternative accounts could explain the present findings, because the distractor stimuli were all presented within a single set of display items.

(Manuscript received January 31, 2007; revision accepted for publication May 18, 2007.) 